Article

\title{
Timing of Drought Triggers Distinct Growth Responses in Holm Oak: Implications to Predict Warming-Induced Forest Defoliation and Growth Decline
}

\author{
J. Julio Camarero *, Magí Franquesa and Gabriel Sangüesa-Barreda \\ Pyrenean Institute of Ecology (IPE-CSIC), Avda. Montañana 1005, Apdo. 202, 50192 Zaragoza, \\ Spain; E-Mails: magifranquesa@gmail.com (M.F.); gsanguesa@ipe.csic.es (G.S.-B.) \\ * Author to whom correspondence should be addressed; E-Mail: jjcamarero@ipe.csic.es; \\ Tel.: +34-976-369-393; Fax: +34-974-363-222.
}

Academic Editor: Steven Jansen

Received: 10 March 2015 / Accepted: 24 April 2015 / Published: 5 May 2015

\begin{abstract}
Droughts negatively impact forests by reducing growth and increasing defoliation leading to forest dieback as the climate becomes warmer and drier. However, the timing and severity of droughts determine how differently or intensively water shortage affects primary (shoot and leaf formation) and secondary growth (stem radial growth based on tree-ring widths). We compare the impact of two severe droughts $(2005,2012)$, showing different climatic characteristics on the growth responses of three Mediterranean holm oak stands in northeastern Spain. We also quantify climate trends and drought severity. Then, we use remote sensing data to infer how those droughts impacted forest productivity. Both droughts were characterized by warm and dry spring conditions leading to reduced budburst, low shoot production, asynchrony in primary growth and decreased productivity and scarce radial growth, particularly in 2005. However, defoliation peaked in 2012 when radial growth showed minimum values and early spring and late summer temperatures reached maximum values. We discuss how uncoupled and resilient are the responses of primary and secondary growth to drought. Finally, these findings are used to gain insight into the drought-related drivers of defoliation in Spanish holm oak forests.
\end{abstract}

Keywords: defoliation; dendroecology; die-off; Quercus ilex; phenology; primary growth; remote sensing; secondary growth; tree ring; water deficit 


\section{Introduction}

Abrupt climatic events such as droughts affect forests and other terrestrial ecosystems [1]. For instance, drought is an important driver of turnover rates of carbon pools at a global scale by influencing forest productivity in biomes experiencing seasonal water shortage [2]. Increased climate variability is likely to increase drought frequency and intensity in some regions of the globe, which could determine future forest productivity and thus alter climate-atmosphere-biosphere feedbacks [3]. Forest responses to droughts are manifold since severe water shortage diminishes leaf carbon fixation through inducing stomatal closure [4,5], triggers growth decline, and forest dieback [6-8]. Therefore, growth responses to drought must be well characterized since they determine to a great extent how much carbon is stored and how strong carbon-sink a forest is.

Droughts are complex climatic phenomena [9]. They involve the stress due to water scarcity caused by low precipitation, but also entail high atmospheric vapor pressure deficits, low soil water-holding capacity, and sometimes heat stress causing the degradation of plant membranes and radiation stress leading to photoinhibition [10]. Heat- and drought-triggered stresses differ and both can contribute to forest dieback [11-13]. Drought stress is expected to be more intense when soil water reserves are minimum, evaporative demand is maximum, and both transpiration rates and leaf area peak, i.e., during summer in most Northern Hemisphere forests.

The complex climatic stresses included in a drought event suggest that its timing and how water deficit interacts with other climatic stressors (e.g., elevated temperatures) can be important drivers of forest responses as drought duration and severity are. For instance, in Southern France drought intensity has increased in the wettest areas by advancing its onset, whereas an earlier end of drought occurred in the driest areas leading to a shift of the dry season without increasing its duration [14]. Periods with successive hot days occur after and during periods with pronounced precipitation deficits in many regions worldwide, and this soil moisture-temperature coupling is very strong in the Iberian Peninsula [15].

Circum-Mediterranean forests may avoid drought stress during the growing season by enhancing leaf shedding in summer thus avoiding excessive loss of water due to transpiration [16]. Recent severe droughts during very warm periods (1994-1995, 2005, 2012) have caused episodes of defoliation and forest dieback affecting Iberian oak [17-19] and conifer forests [20]. Iberian forests have shown defoliation and growth decline in response to recent droughts, which have probably altered the period for optimum growth conditions usually spanning spring and autumn. Thus, they constitute a good system to assess how forests respond to droughts of different seasonal timings and climatic characteristics (intensity, duration).

Different forest growth responses to drought are expected depending on the tree phenology and on which growth variables are considered [7]. For instance, drought can induce a decline in primary growth (e.g., bud development, shoot elongation, leaf expansion) or reduce secondary growth (e.g., stem wood formation), but water shortage can also trigger defoliation. Then, we hypothesized that the timing of warming and drought should have differential tree growth responses: while primary growth is sensitive to winter-spring warming, secondary growth is sensitive to summer-autumn warming. In other words, primary or secondary growth will react in different ways to droughts based on their 
contrasting phenological patterns (distinct timings) or depending if they are preceded by previous droughts, i.e., drought's legacy [21].

Here, we explore the responses to droughts of different timings and intensities in holm oak (Quercus ilex). Holm oak is a very abundant tree species across the Western Mediterranean Basin where it faces seasonal drought by displaying an elevated phenological, morphological and physiological variability [16]. We characterize several growth variables related to primary (shoot production and biomass, defoliation, forest cover and productivity derived from remote-sensing data) and secondary growth (tree-ring width). Then, we discuss how resilient are holm oak forest in response to different types of droughts by showing contrasting growth responses (e.g., defoliation levels) considering the ability of this species to resprout and rebuild its canopy thus reducing the probability of eventual tree death [18]. Finally, we use our findings to discuss the trends observed in Spanish defoliation data of holm oak forests, which show rising rates of leaf loss related to ongoing heat stress and successive droughts [22-24].

\section{Materials and Methods}

\subsection{Study Sites and Species}

We studied three coppice stands of Quercus ilex subsp. ballota (Desf.) Samp L. (holm oak), which is an evergreen oak sub-species mainly present in areas of the Iberian Peninsula subjected to continental Mediterranean climate, i.e., it is well adapted to dry and cold conditions [25]. The coppice forests are located on a relatively flat area in Arascués, Aragón, in northeastern Spain $\left(42^{\circ} 14^{\prime} \mathrm{N}\right.$, $0^{\circ} 27^{\prime} \mathrm{W}, 650 \mathrm{~m}$ a.s.1., Figure 1a). The mean basal area of the forest is $31.6 \mathrm{~m}^{2} \cdot \mathrm{ha}^{-1}$, and the understory is dominated by shrubs, such as Rhamnus alaternus L. and Quercus coccifera L., with some dispersed Juniperus oxycedrus L. trees usually growing in gaps. The study forests have not been managed (thinning, coppicing) for the last 50 years (see more details on the sampling site in [26]). Soils are rocky, basic, rich in clay and shallow with a mean depth of $c a .50 \mathrm{~cm}$. The climate is Mediterranean with continental influence and the mean annual temperature is $13.5{ }^{\circ} \mathrm{C}$ and total annual precipitation is $550 \mathrm{~mm}$. July and January are the warmest and coldest months, respectively. Climatic data correspond to the period 1951-2014, and they were obtained from the Monflorite-Huesca station $\left(42^{\circ} 05^{\prime} \mathrm{N}, 0^{\circ} 20^{\prime} \mathrm{W}\right.$, $541 \mathrm{~m}$ ), located $c a .17 \mathrm{~km}$ from the study site.

Holm oaks usually retain three cohorts of leaves and produces diffuse to semi-ring porous wood [16]. Most primary (shoot and leaf development) and secondary (stem wood increment) growth occur from April to June whilst leaf shedding peaks from June to October [16]. 

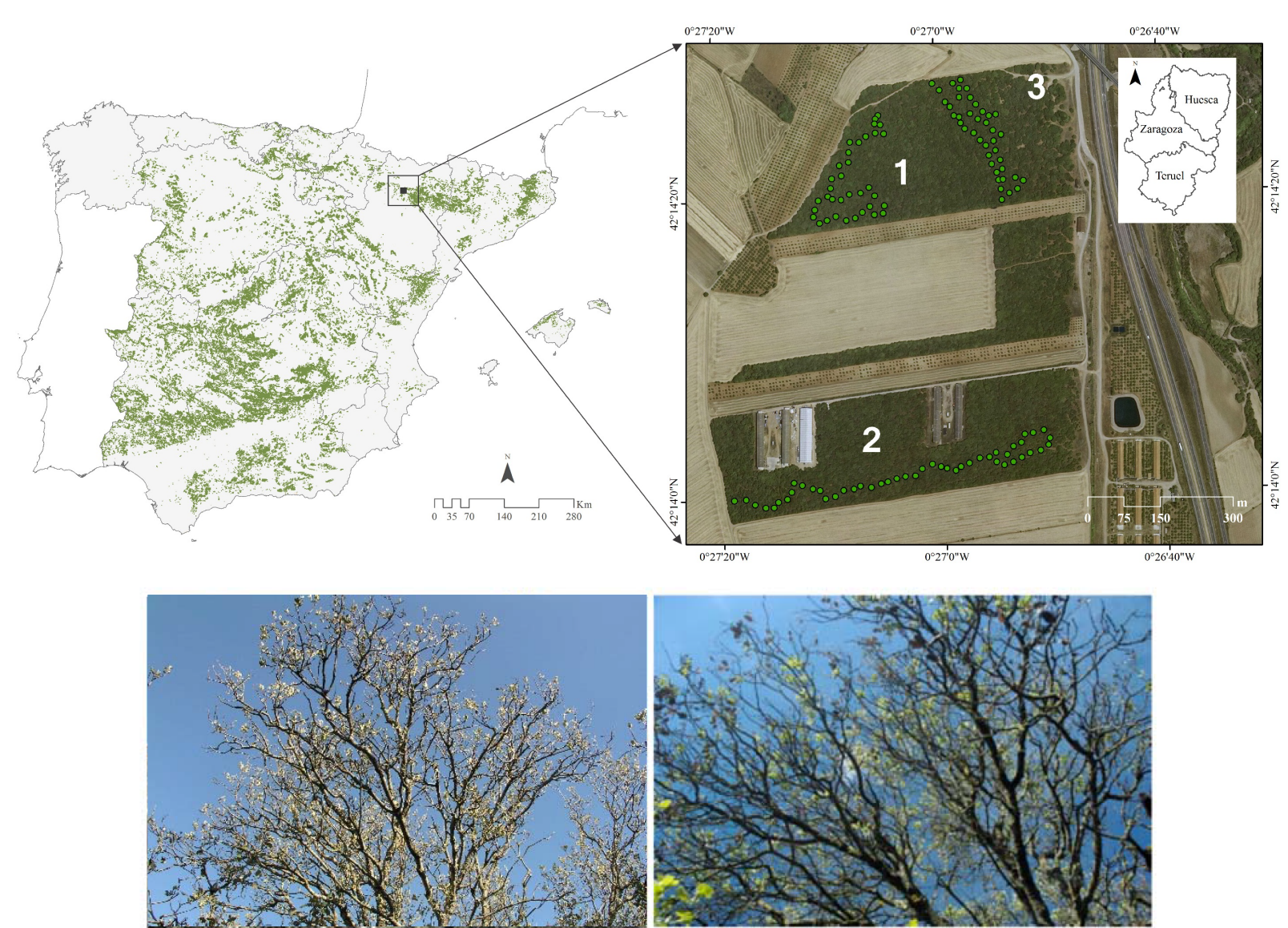

(a)
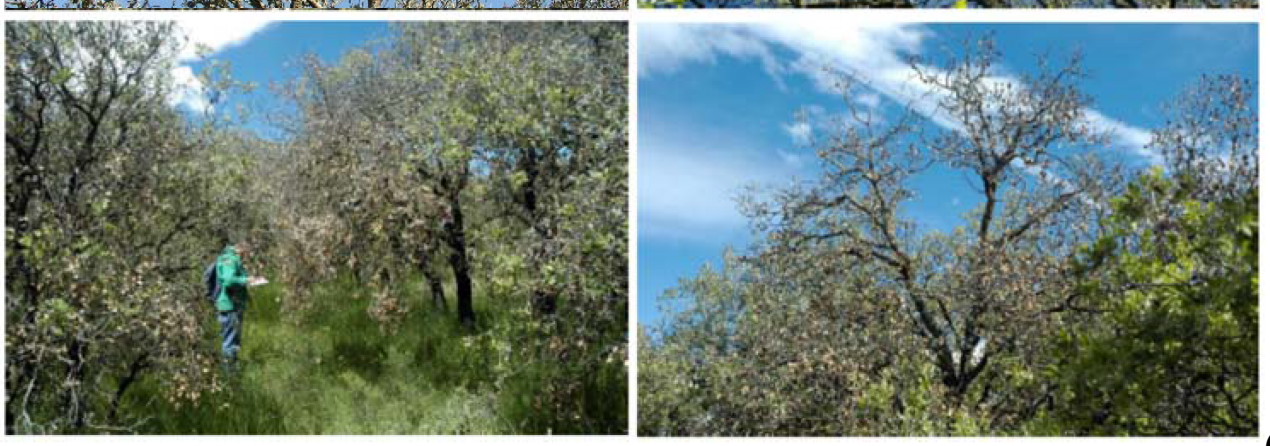

(b)

Figure 1. (a) Distribution of holm oak in Spain (green patches) and location of the studied holm oak forests (sites 1, 2 and 3) and trees (dots) with (b) views of defoliated trees after the severe 2005 (uppermost left photograph) and 2012 (rest of images) droughts. The nearby sites 1 and 3 were considered the same sampling unit regarding primary growth and remote sensing data.

\subsection{Field Sampling}

In the study area, we selected three stands of size 3-4 ha located at least $500 \mathrm{~m}$ apart, and in each stand 50 trees were randomly selected along transects, mapped using a GPS and tagged (Figure 1b). Their size and structure were measured (diameter at breast height, henceforth dbh; height; number of stems per tree). Sampled trees were at least $20 \mathrm{~m}$ apart. Neither size (dbh, height) nor the number of stems per tree significantly differed between the three stands so we show the mean ( $\pm \mathrm{SE}$ ) values of all trees which were: $\mathrm{dbh}=12.3 \pm 0.3 \mathrm{~cm}$; height $=4.8 \pm 0.1 \mathrm{~m}$; and number of stems per tree $=4 \pm 1$. 
The basal area was the lowest in stand $2\left(30.0 \mathrm{~m}^{2} \cdot \mathrm{ha}^{-1}\right)$, where soils were also shallow (mean depth $c a$. $30 \mathrm{~cm}$ ). Since we considered crown cover as a proxy of tree vigor [27], every autumn (see below the mean sampling date), the percentage of defoliation of each tree was estimated to the nearest 5\% [28]. Since estimates of defoliation vary among observers and places, the data were always recorded by the first author, who compared every tree with a reference nearby tree with maximum amount of foliage, i.e., the field estimates of defoliation correspond to relative defoliation referred to the study stand.

\subsection{Climate Data}

We obtained daily and monthly values of the following climatic variables: mean maximum and minimum temperatures, precipitation $(\mathrm{P})$, estimated potential evapotranspiration (PET) and water balance (P-PET). Data were gathered from the Monflorite-Huesca meteorological station for the period 1951-2014. The time series of the climate variables were carefully checked to assure homogeneity. The monthly PET was estimated using monthly values of mean temperature, daily temperature range and solar radiation following the Hargreaves-Samani method [29].

To estimate the effect of drought intensity on tree growth, we used the Standardized Precipitation-Evapotranspiration Index (SPEI), which is a multi-scalar drought index with negative and positive values corresponding to dry and wet periods, respectively [30]. The time period from precipitation to water usage by forests depends on climate seasonality and tree phenology, which makes the time scale over which water deficits accumulate critical. This is why growth must be compared with drought indices calculated at several timescales, which allow monitoring how usable are water resources by trees. The SPEI monthly values for the period 1950-2014 at 1-16 months long scales were obtained for the $0.5^{\circ}$ grid located over the study area. The use of the SPEI allows quantifying the effects of drought index on radial growth at different time scales and considering diverse drought intensities [31].

In the case of defoliation data obtained for the whole conterminous Spain and the Balearic Islands (see section Spanish defoliation data) we obtained monthly climatic variables (mean temperatures and total precipitation) for the period 1990-2012 from the Climate Research Unit TS3.1 database, which provides homogenized and quality-controlled data at $0.5^{\circ}$ spatial resolution [32]. SPEI data were also obtained for Spain as described above. We selected the region delimited by coordinates $36.75^{\circ}-43.25^{\circ} \mathrm{N}$ and $7.25^{\circ} \mathrm{W}-3.25^{\circ} \mathrm{E}$ to get these data since this area covers most of the Spanish holm oak plots with defoliation data. These data were downloaded using the Climate Explorer web page.

\subsection{Primary Growth and Phenology}

From 2004 to 2012, we made visual estimates of shoot production in all trees during spring (mean sampling date of year was mean $\pm \mathrm{SE}=141 \pm 4$, i.e., 20 May) and autumn (mean sampling date of year was $296 \pm 3$, i.e., 22 October). We randomly took two to three 3-year old branches from the upper crown of each tree and counted the number of long shoots (dolichoblasts). Then, we used the following scale based on the number of new shoots produced per 3-year old branch: 0,0 shoots; 1,1 shoot; 2 , 2-3 shoots; 3, 4-5 shoots; $4,>5$ shoots. 
We also assessed the timing of primary growth and male flowering in spring from 2005 to 2012 by using a semi-quantitative scale of seven successive phenological stages [33]: 1, bud swelling; 2, early budburst; 3, budburst and initial stage of shoot elongation; 4, active shoot elongation, male flowers start appearing; 5, advanced shoot development, mature male flowers, no bud bursting; 6, very advanced shoot development and flowering, shedding of male flowers starts; and 7, finished shoot development and mature male flowers are shed. Each stage was defined when $50 \%$ of the swelling buds, emerging leaves and flowers or expanding shoots were recognizable on the individual tree canopy.

To estimate how stem and leaf biomass changed, intensive sampling of branches was carried out in October from 2004 to 2008 . We randomly selected eight trees in each stand to measure the dry mass of stems and leaves ( $n=24$ trees). We collected at random two 3-year-old branches from the mid crown of each tree. We divided the branches into stems and leaves, according to their year of formation and considering three annual cohorts. Fractions corresponding to the stems and leaves of the three cohorts were oven dried to a constant mass at $60{ }^{\circ} \mathrm{C}$ to obtain dry mass (see a more detailed description in [26]). Using the dry mass of those branch fractions we developed a foliar index defined as the ratio between the dry mass of all leaves and that of all shoots. Since the foliar index did not significantly differ between nearby sites 1 and 3 (Mann-Whitney test, $p>0.05$ ), we present mean values $( \pm \mathrm{SE})$ for combined sites 1 and 3 and separately for site 2 each study year. Shoot amount was monitored for a longer period (2004-2012) than the quantification of branch dry mass (2004-2008) because the second proxy of primary growth is very time consuming and presented a low year-to-year variability. For instance, the mean 3-year old branch dry mass was $2.91 \mathrm{~g}$ for the 2004-2012 period, and the minimum value was observed in 2005 (1.70 g). In addition, the number of shoots produced during a year was significantly related to the dry mass of shoots and leaves formed during that year $(r=0.87, p=0.05)$.

\subsection{Remote Sensing Data: Vegetation Indices}

Remote-sensing data were used to estimate changes in forest productivity by using several vegetation indices. Images were acquired from Landsat-5 and Landsat-7 sensors. We used Landsat Surface Reflectance (SR) images processed with LEDAPS atmospheric correction [34]. All the images were acquired from the U.S.G.S. webpage. We used 90 SR images (path 199/031) averaged over the 2000-2014 period, with a mean of 6 images per year and minimum and maximum values of 2 (e.g., 2002) and 10 (e.g., 2007) images, respectively. The monthly mean number of images was 7.5 with minimum and maximum values taken in January (3 images) and August (13 images), respectively. Among the numerous vegetation indices available [35], we selected for this study two indices based on previous analyses: (i) the Normalized Difference Vegetation Index (NDVI), which is widely used to estimate the fraction of the photosynthetically active radiation absorbed by the canopy [36]; and (ii) the Normalized Difference Infrared Index (NDII), which is sensitive to changes in water content of tree canopies [37]. Finally, we selected 59 pixels (each pixel occupies $30 \mathrm{~m} \times 30 \mathrm{~m}$ ) encompassing an area of 5.3 ha fully occupied by holm oak canopies for the combined stand, including sites 1 and 3 and 16 pixels for the site 2 to extract the reflectance values. We calculated the average value of the vegetation indices for each month and year. 


\subsection{Secondary Growth}

We used dendrochronology to retrospectively quantify radial growth of study trees [38]. Secondary growth was measured by extracting two radial cores per tree in late 2014 at dbh $(1.3 \mathrm{~m})$ using a Pressler increment borer. We sampled the same trees in each site where branches have been taken to quantify shoot biomass ( $n=24$ trees, 8 per site). We avoided sampling trees that produced abundant acorns, a previous masting event that occurred in 2003, since this could affect radial growth [26]. Wood samples were sanded until tracheids were visible and then visually cross-dated. Once dated, we measured the tree-ring widths to the nearest $0.01 \mathrm{~mm}$ using a binocular scope and a LINTAB measuring device (Rinntech, Heidelberg. Germany). The accuracy of visual cross-dating was checked with the program COFECHA, which calculates moving correlations between each individual series and the mean site series [39].

The biological and geometric trends not related to climate were removed to emphasize the climatic signal and to maximize the relationship between climatic variables and radial growth [38]. Each ring-width series was detrended using a Hugershoff growth curve, which was flexible enough to preserve yearly variability. This allowed transforming tree-ring widths to dimensionless growth indexes by dividing observed ring width values by fitted values. The resulting series were standardized and pre-whitened by autoregressive models to remove most temporal autocorrelation. Then, a biweight robust mean was computed on a year-by-year basis to obtain a residual chronology, which was used in all subsequent analyses. These procedures were done using the ARSTAN software [40].

The mean ring-width chronology was characterized by calculating the following statistics over the common interval 1960-2014: first-order autocorrelation (AC1) of raw tree-ring widths; mean sensitivity (MSsx) of residual indices to quantify the year-to-year variability in width of consecutive tree rings; mean between-trees correlation to measure the similarity in ring-width indices among trees; and the Expressed Population Signal (EPS) which measures the statistical quality of the mean site chronology as compared with a perfect infinitely replicated chronology $[41,42]$.

Finally, to detect time-dependent responses of radial growth to climate the ring-width residual chronology was correlated, using Pearson correlation coefficients, with mean minimum and maximum temperatures and summed precipitation for the period 1960-2014 considering 5-, 15- and 25-day long periods following [43].

\subsection{Spanish Defoliation Data}

Defoliation data of holm oak forests located in the conterminous Spain and the Balearic Islands were gathered from the ICP Forests program [44] and updated based on recent analyses of this data set $[23,24]$. They correspond to the ICP Level I network distributed in Spain which allowed obtaining visual estimates of annual defoliation (measured in summer) since 1987 in circular plots including 24 dominant trees and established on a $16 \times 16 \mathrm{~km}$ grid $[23,24]$. We limited our analyses to the period 1990-2012 when sample size was representative enough [24]. Currently, the assessed holm oaks are 3243 trees distributed in 198 Level-I plots with a mean dbh of $26.2 \mathrm{~cm}$ and located at a mean elevation of $725 \mathrm{~m}$ a.s.1. [23]. 


\subsection{Statistical Analyses}

Climate trends were quantified using the Kendall tau statistic. Associations between climate and growth variables were assessed using either the Pearson $(r)$ or the Spearman $\left(r_{s}\right)$ correlation coefficients in the case of variables following or not following normal distributions. Comparisons between years regarding the frequencies of trees showing different phenological stages were performed by using $\chi^{2}$ tests. To compare mean values of growth variables (foliar index, shoot production, phenological stages) between stands we used the robust Mann-Whitney $U$ test. Lastly, to test if the mean NDVI monthly values differ from specific values measured in the two driest years $(2005,2012)$ we used one-way $t$-tests. All statistical analyses were done with the $\mathrm{R}$ statistical software [45].

\section{Results}

\subsection{Climate Trends and Long-Term Tree-Ring Responses to Droughts}

In the study area all seasonal temperatures are rising significantly $(p<0.05)$ since the early 1950s, particularly in summer (mean rate $+0.04{ }^{\circ} \mathrm{C}$ year ${ }^{-1}$ ), followed by autumn $\left(+0.03{ }^{\circ} \mathrm{C}\right.$ year $\left.{ }^{-1}\right)$, whereas winter (mean rate $-0.25 \mathrm{~mm}$ year $^{-1}$ ) and summer (mean rate $-0.31 \mathrm{~mm} \mathrm{year}^{-1}$ ) precipitations are also decreasing (Figure 2a,b). The 2005 and 2012 droughts caused relative radial-growth reductions of 50\% and 55\%, respectively. Such growth decline was much more intense than previous growth reductions of $c a .37 \%$ observed in the 1967 and 1994 droughts. The August SPEI calculated at eight-month-long scales was the climate variable most tightly related $(r=0.46, p=0.0006$, period 1960-2014) to the holm oak ring-width index (Figure 2c). Both variables showed very low values during years characterized by severe droughts such as 2005 and 2012. The 2005 drought was very intense in spring when precipitations were very low, whilst the 2012 drought was characterized by a previous dry and hot winter and warm spring-to-summer conditions. Severe droughts also occurred in autumn during 2004 and 2007.

\subsection{Primary Growth Responses to Drought}

During the period 2004-2012, mean defoliation never exceeded 25\%, except in 2005 (mean defoliation $35 \% \pm 4 \%, 14 \%$ trees with defoliation $>75 \%$ ) and 2012 (mean defoliation $44 \% \pm 4 \%, 22 \%$ trees with defoliation $>75 \%$ ). After these two dry years we observed uncommon growth patterns such as abundant epicormic sprouting along the stem and also defoliation in many holm oak trees (Figure 1b). In 2012, other tree species, such as J. oxycedrus, also presented brown foliage and loss of needles, particularly in the basal half crown. In 2012 eight trees out of 150 (5\%) were completely defoliated. Remarkably, only two of those trees were dead one year later representing an annual mortality rate of $1.3 \%$. However, the responses of primary growth to the 2005 and 2012 droughts differed. In 2005 many trees produced abundant epicormic shoots and primary growth was much suppressed in spring and autumn (Figure 3), whereas old leaves were shed by some trees in autumn. Contrastingly, in 2012 the overall production of long shoots was very low in autumn when defoliation due to the shedding of old leaves was more widespread than in 2005 . However, a few trees (8\%) 
produced autumn shoots in response to late rains, which is a rare phenological response in the study site usually subjected to cold autumn and winter conditions.
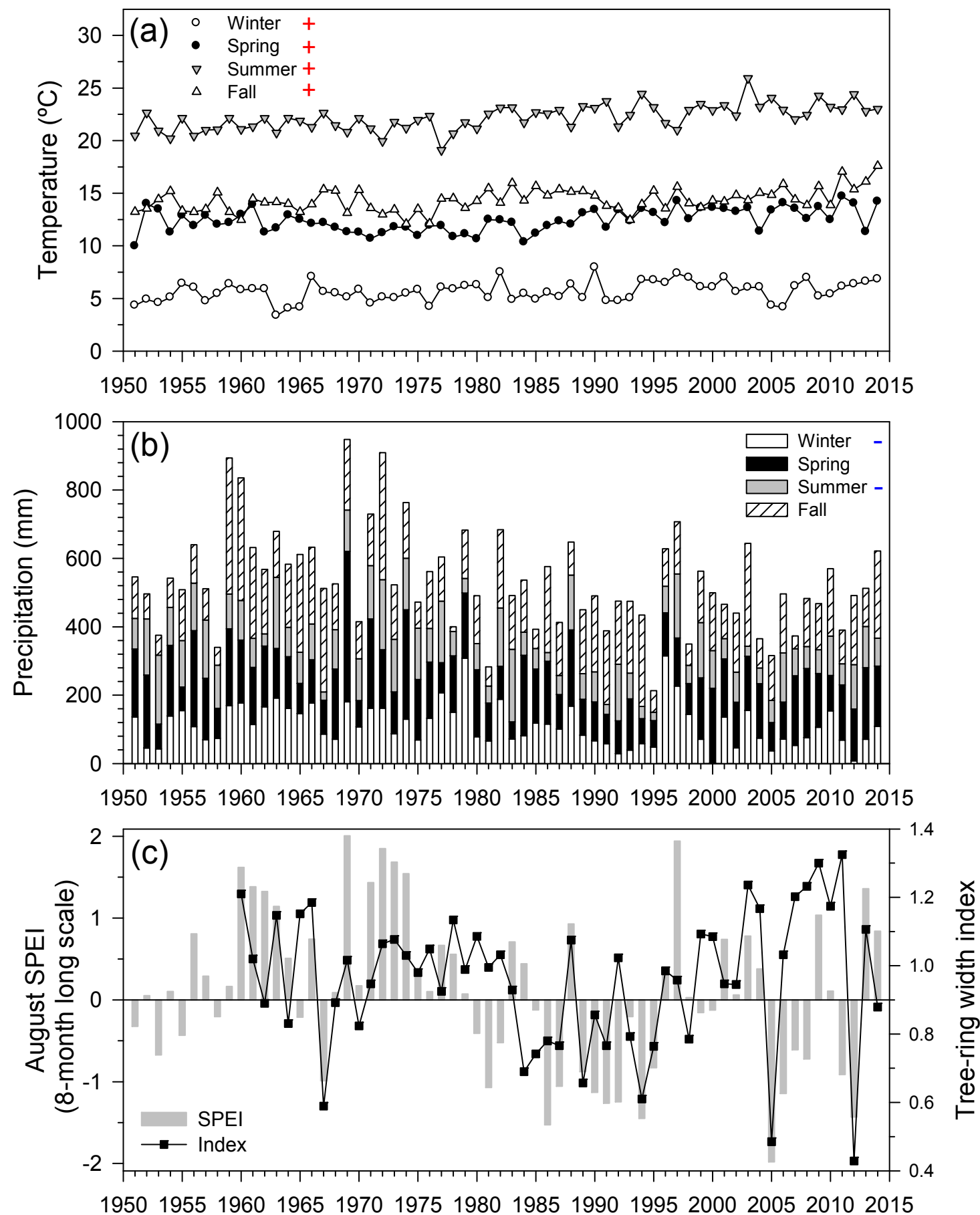

Year

Figure 2. Seasonal climatic trends $(\mathbf{a}, \mathbf{b})$ and drought patterns (August Standardized Precipitation-Evapotranspiration Index, SPEI, calculated at eight-month-long scales) for the period 1951-2014 in the study area as related to holm oak ring-width index (c). In the two upper plots the symbols after the seasons indicate either positive (all seasonal temperatures) or negative (winter and summer precipitation) significant $(p<0.05)$ trends based on the Kendall tau statistic. 


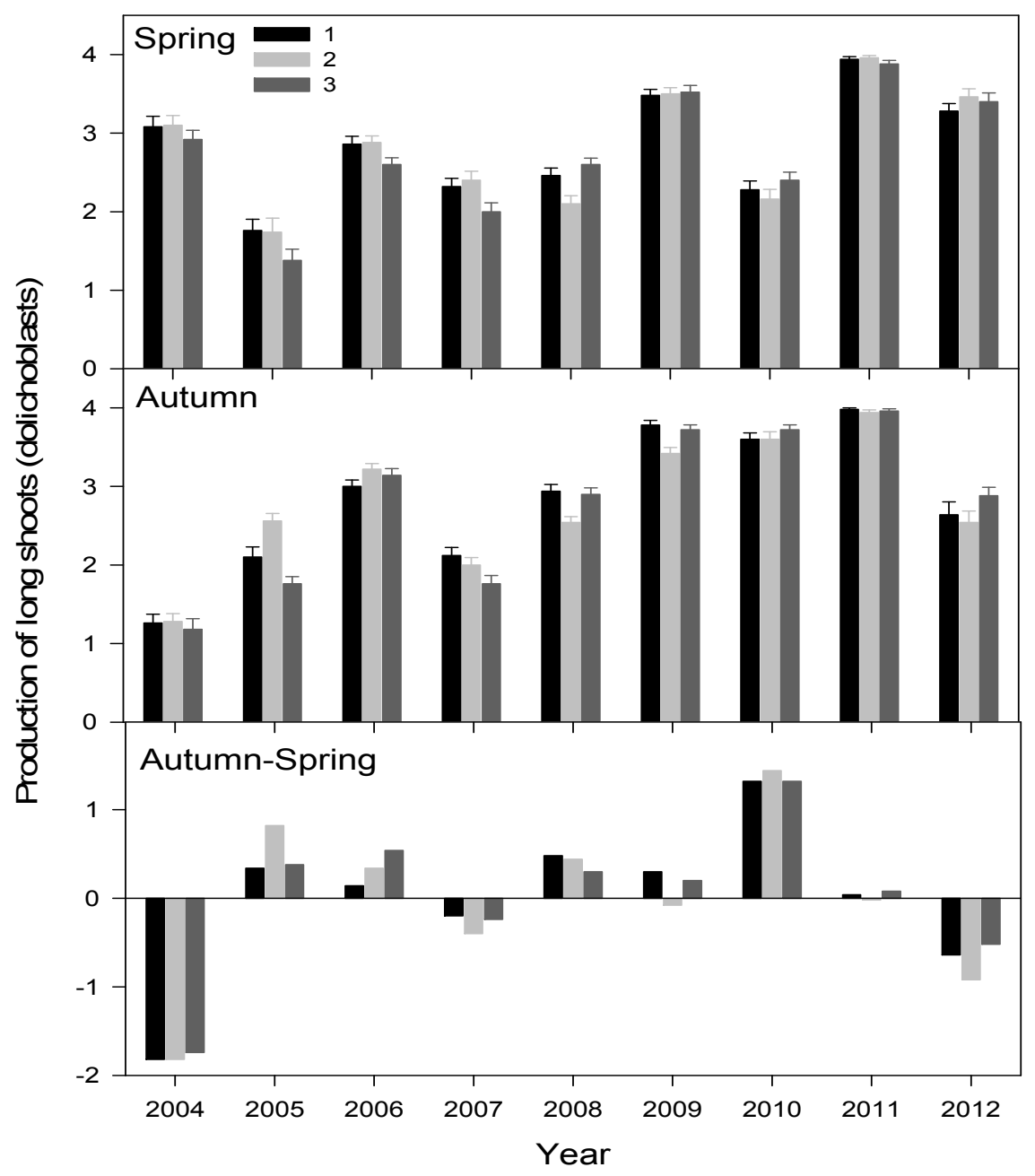

Figure 3. Estimated production of long shoots or dolichoblasts (means $\pm \mathrm{SE}$ ) in spring and autumn in the three holm oak study stands from 2004 to 2012. The lowermost plot shows the difference between mean shoot production in autumn and spring.

From 2004 to 2012 the autumn shoot production was always higher than in spring (that difference peaked in 2010), excepting in 2004, 2007 and 2012. It is also remarkable that the sites showing the most similar shoot production were 1 and 3 both in spring $\left(r_{s}=0.98, p<0.001\right)$ and in autumn $\left(r_{s}=0.99, p<0.001\right)$. Therefore sites 1 and 3 behaved similarly regarding primary growth and this justifies grouping them in the study of remote-sensing data.

The low shoot production in spring 2005 was linked to a high level of phenological asynchrony among trees with some showing swollen buds and no bud bursting, whereas others presented shoots showing advanced development (Figure 4). The distribution of phenophases during the two drought years $(2005,2012)$ significantly $(p<0.001)$ differed from the mean of the remaining years $(2005$, $\left.\chi^{2}=47.1 ; 2012, \chi^{2}=36.6\right)$. Since phenological stages did not significantly differ between sites (Mann-Whitney tests, $p>0.05$ ) we present these data for the whole study area. Specifically, 79\% trees presented well developed shoots and mature male flowers from 2006 to 2012 in late May, whereas in 2005 only $24 \%$ of trees formed fully developed shoots and $45 \%$ of trees presented no bud bursting (Figure 4). The distribution of trees according to the phenological stage was significantly different in 2005 compared with mean distribution of the period 2006-2012 $\left(\chi^{2}=68.3, p<0.001\right)$. This was also 
the case when comparing the 2012 and 2005-2011 distributions of phenological stages, despite differences were less important $\left(\chi^{2}=12.2, p=0.02\right)$. It is remarkable that budburst during the dry 2005 spring was lower than in 2011 , when $8 \%$ of trees did not show budburst but sampling was done very early (late April) compared with other years (late May).

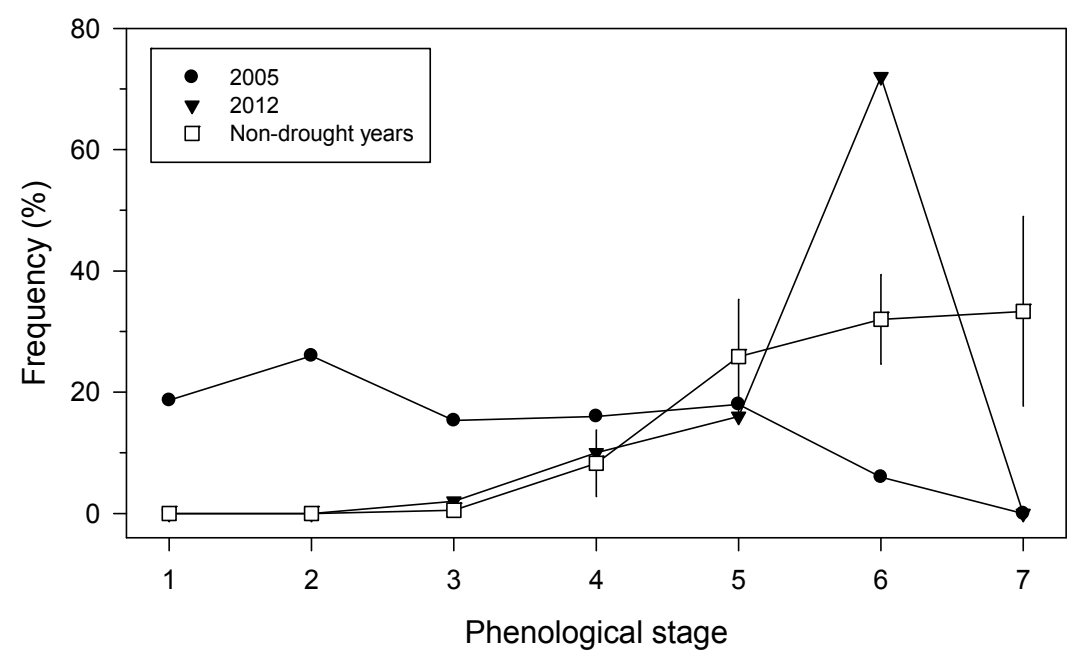

Figure 4. Frequency of holm oak trees $(n=150)$ classified in seven spring phenological stages ( 1 to 7 ) based on their spring primary growth during the period 2005-2012. The plot shows the two drought years $(2005,2012)$ and the means $( \pm \mathrm{SE})$ of non-drought years (excluding 2011 when sampling was done very early, in late April, compared with other years when phenology was recorded in late May). Levels 1 and 7 correspond to the less (swollen buds) and most (finished shoot and male flower formation) advanced stages of primary growth, respectively.

\subsection{Canopy-Scale Responses}

We found that the foliar index was positively related to the NDVI $(r=0.93, p<0.01)$ and also to the NDII $(r=0.84, p<0.01$ ), but not to tree-ring width (see Figure 5 and Table 1). It is also remarkable that the variability in primary growth among trees and in productivity among forests pixels both increased in 2005 as compared with the rest of years. For instance, the coefficient of variation of the foliar index was $49 \%$ in 2005 , being significantly higher $(t=-6.8, p=0.0003)$ than in the rest of years when it averaged $33 \%$. Tree-ring width was neither significantly related to NDVI nor with the foliar index except that all variables showed abrupt decreases in response to the 2005 drought. The reduction in radial growth caused by the 2005 drought produced more pronounced "legacy effects", i.e., it was less resilient, than the decreases in primary growth and productivity, despite the series are too short to draw robust conclusions. Radial growth took two years to recover values similar to those observed before the drought (tree ring width in 2006 was significantly lower than in $2004 ; t=-4.04$, $p<0.01$ ), whilst primary growth took only one year (Figure 5). 


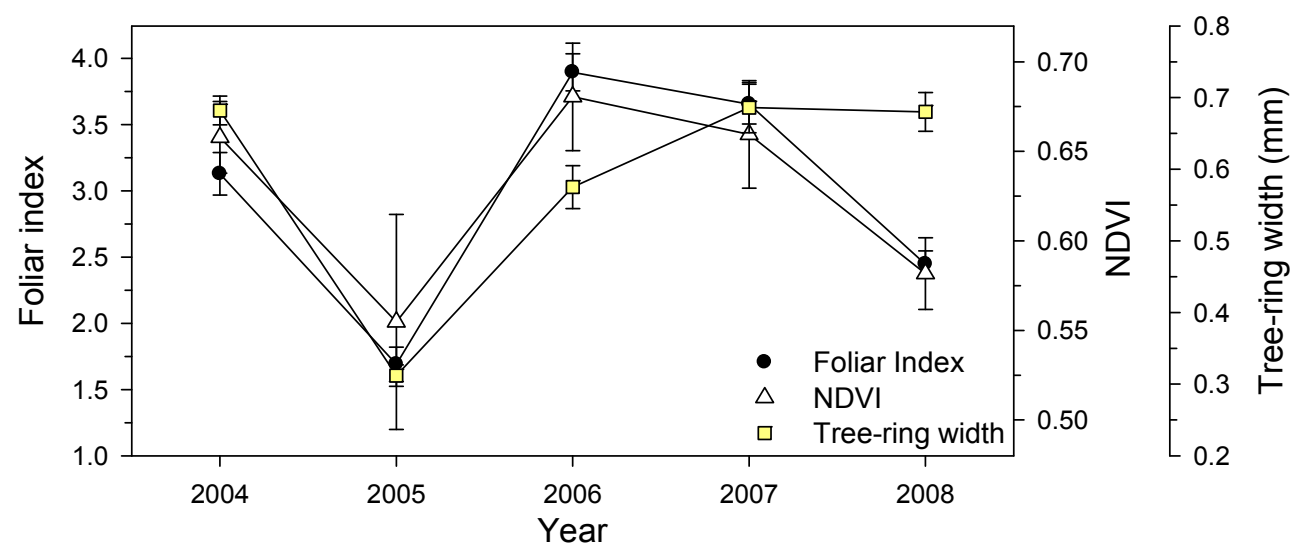

Figure 5. Associations observed between the foliar index (ratio between the dry mass of all leaves and the mass of all shoots), the Normalized Difference Vegetation Index (NDVI) and tree-ring width. Data are means $\pm \mathrm{SE}$.

Table 1. Values of the foliar index (means $\pm \mathrm{SE}$ ) are compared with the vegetation indices for sites 1-3 and 2. All remote sensing data refer to October when primary growth was finished, excepting the 2004 images, which were taken in June. Note that the foliar index was quantified based on biomass data from branches sampled in October. Indices abbreviations are: NDII, Normalized Difference Infrared Index; NDVI, Normalized Difference Vegetation Index.

\begin{tabular}{ccccc}
\hline \multirow{2}{*}{ Year } & \multirow{2}{*}{ Sites } & \multirow{2}{*}{ Foliar Index } & \multicolumn{2}{c}{ Vegetation Indices } \\
\cline { 4 - 5 } & & & NDII & NDVI \\
\hline \multirow{2}{*}{2004} & $1-3$ & $3.08 \pm 0.15$ & 0.254 & 0.658 \\
& 2 & $3.18 \pm 0.18$ & 0.252 & 0.657 \\
2005 & $1-3$ & $2.08 \pm 0.11$ & 0.121 & 0.570 \\
& 2 & $1.83 \pm 0.08$ & 0.100 & 0.539 \\
2006 & $1-3$ & $3.82 \pm 0.12$ & 0.313 & 0.690 \\
& 2 & $3.95 \pm 0.14$ & 0.306 & 0.671 \\
2007 & $1-3$ & $3.45 \pm 0.16$ & 0.270 & 0.674 \\
& 2 & $3.86 \pm 0.15$ & 0.242 & 0.644 \\
2008 & $1-3$ & $2.36 \pm 0.08$ & 0.254 & 0.584 \\
& 2 & $2.53 \pm 0.09$ & 0.224 & 0.579 \\
\hline
\end{tabular}

The summer NDVI values in 2005 (June NDVI departure from the mean or anomaly $=-0.08$, July NDVI anomaly $=-0.06$ ) and 2012 (August NDVI anomaly $=-0.07)$ were significantly $(p<0.01)$ lower than the 2000-2014 mean values, which presented maximum values during winter months (Figure 6). Therefore, remote-sensing data captured the changes in productivity in response to very dry conditions (particularly in spring 2005) and very warm temperatures (particularly in summers 2005 and 2012, and also in winter 2011-2012 and spring 2012; note also the low temperatures recorded in January-February, 2005). 


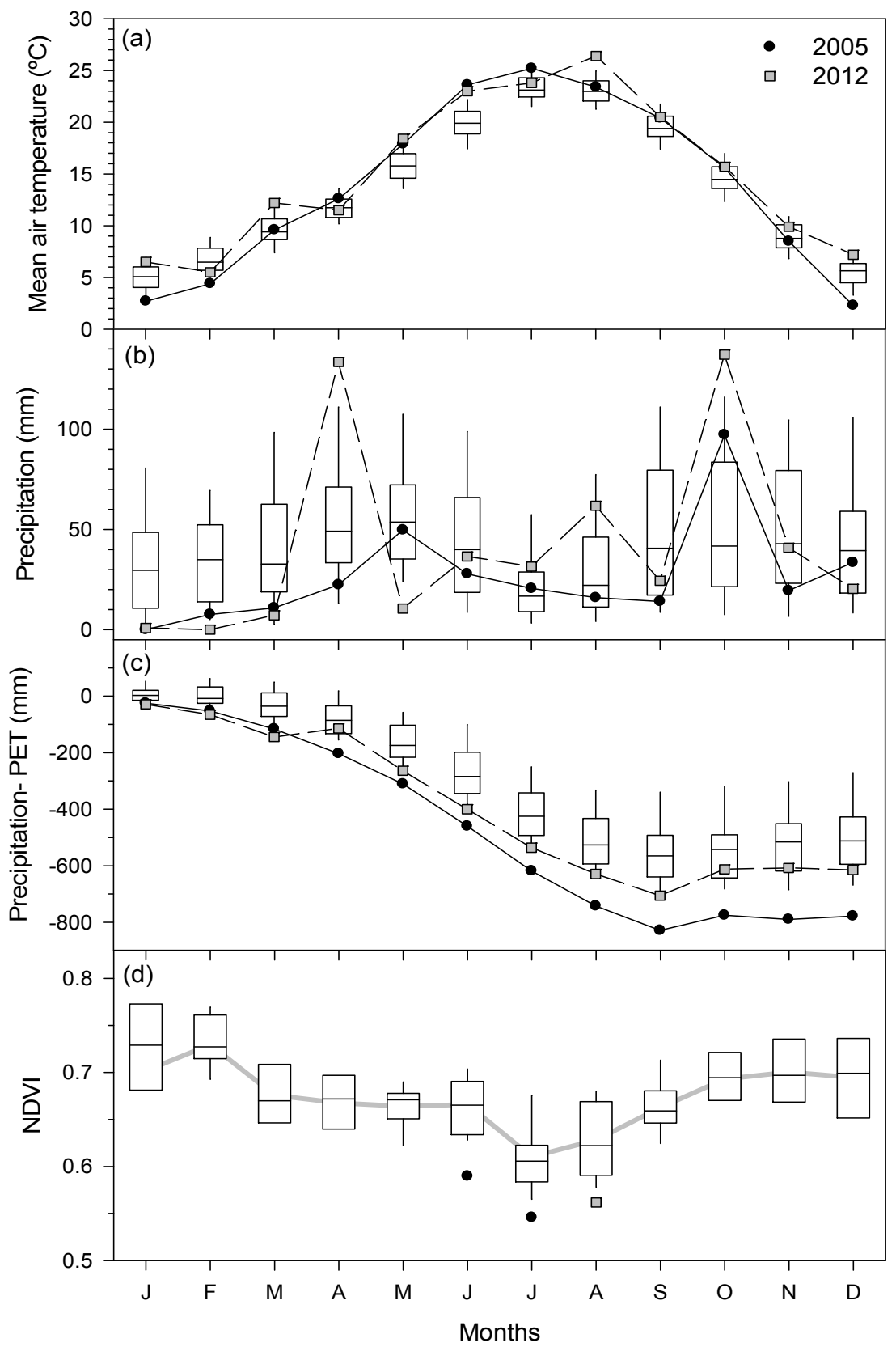

Figure 6. Monthly mean temperatures (a), precipitation (b) and cumulative water balance (c) (difference between precipitation and potential evapotranspiration-PET) for the period 1951-2014 as compared with monthly mean (period 2000-2014) NDVI values (d). In the plots 2005 (black circles) and 2012 (grey squares) values are compared with the mean values represented as box plots. In the lowermost plot (d), the grey line shows the mean NDVI values and the symbols indicate NDVI values for 2005 and 2012 significantly different than the mean NDVI $(t$-tests, $p<0.01)$. 


\subsection{Secondary Growth Responses to Climate and Drought}

In total, 18 out of 24 sampled trees were successfully cross-dated and showed a mean correlation in their ring-width series of 0.24 (Table 2). The mean ring width was $0.79 \mathrm{~mm}$ and the MSx was 0.47 , confirming a high year-to-year variability and suggesting a high responsiveness to climate. In fact, holm oak radial growth responded positively to cold and wet conditions in previous winter, spring and mainly in June, when high growth rates are observed, whereas very warm conditions in March and July were related to the formation of narrow rings (Figure 7a). Radial growth mostly responded to 6-8-month-long SPEI values from June to August (Figure 7b; see also Figure 2c). At short time scales, growth was positively related to high precipitation in mid-February and early June at five-day-long scales, whilst high mid-June to early-July temperatures at 15-25-day-long scales were linked to reduced growth (Figure 7c). Regarding the water balance, the ring-width indices were positively related to the summed water balance from June to July $(r=0.31, p=0.02)$.

(a)

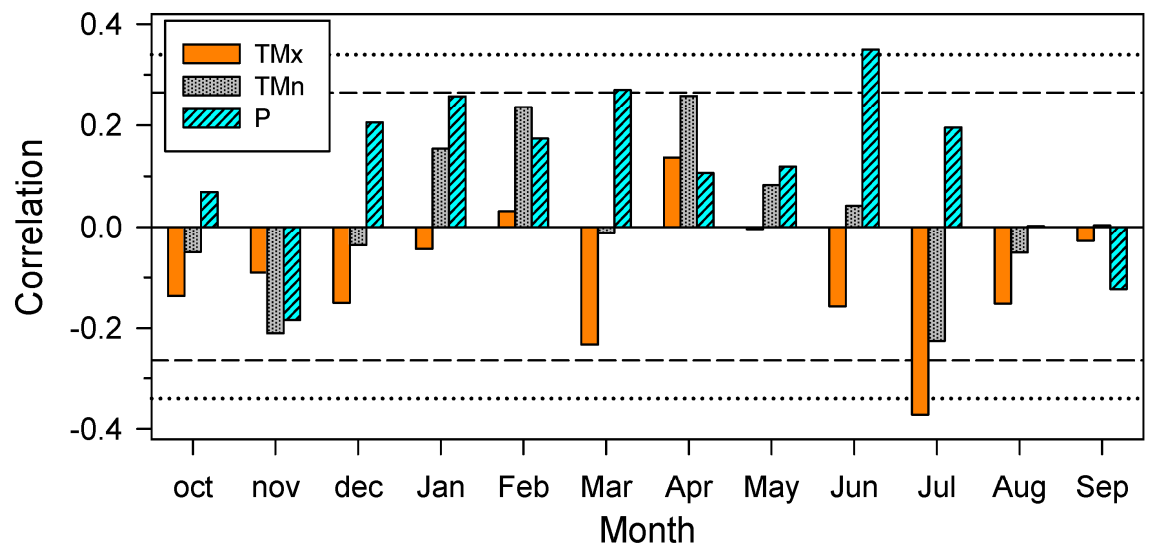

(b)

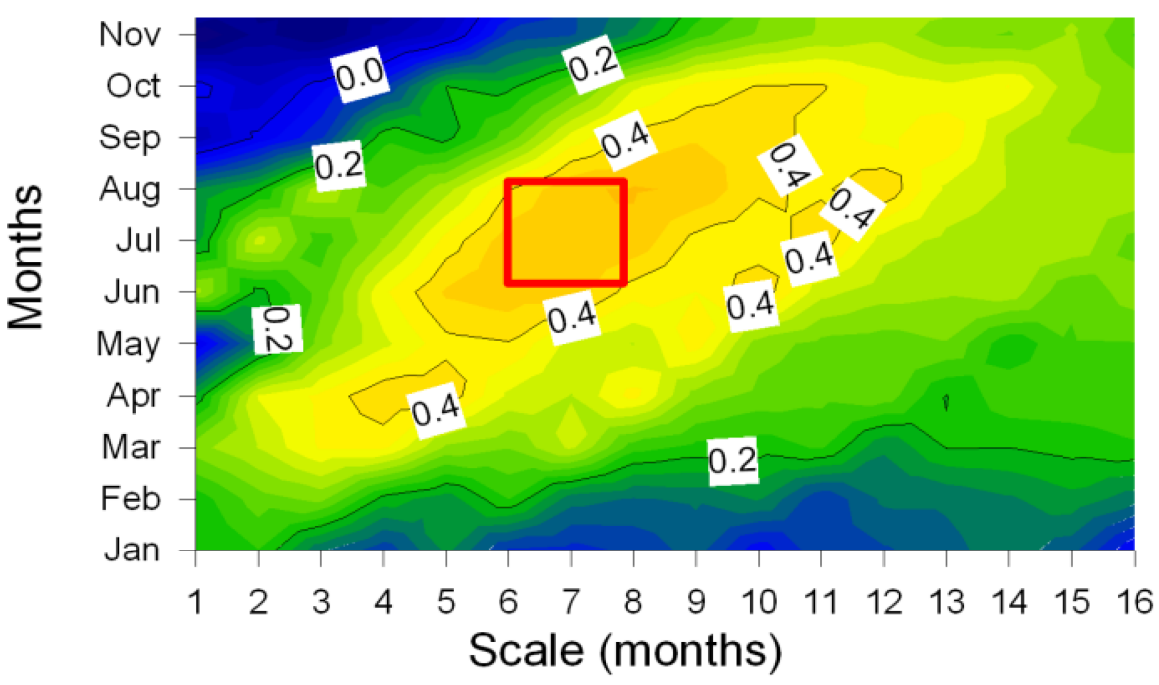

Figure 7. Cont. 


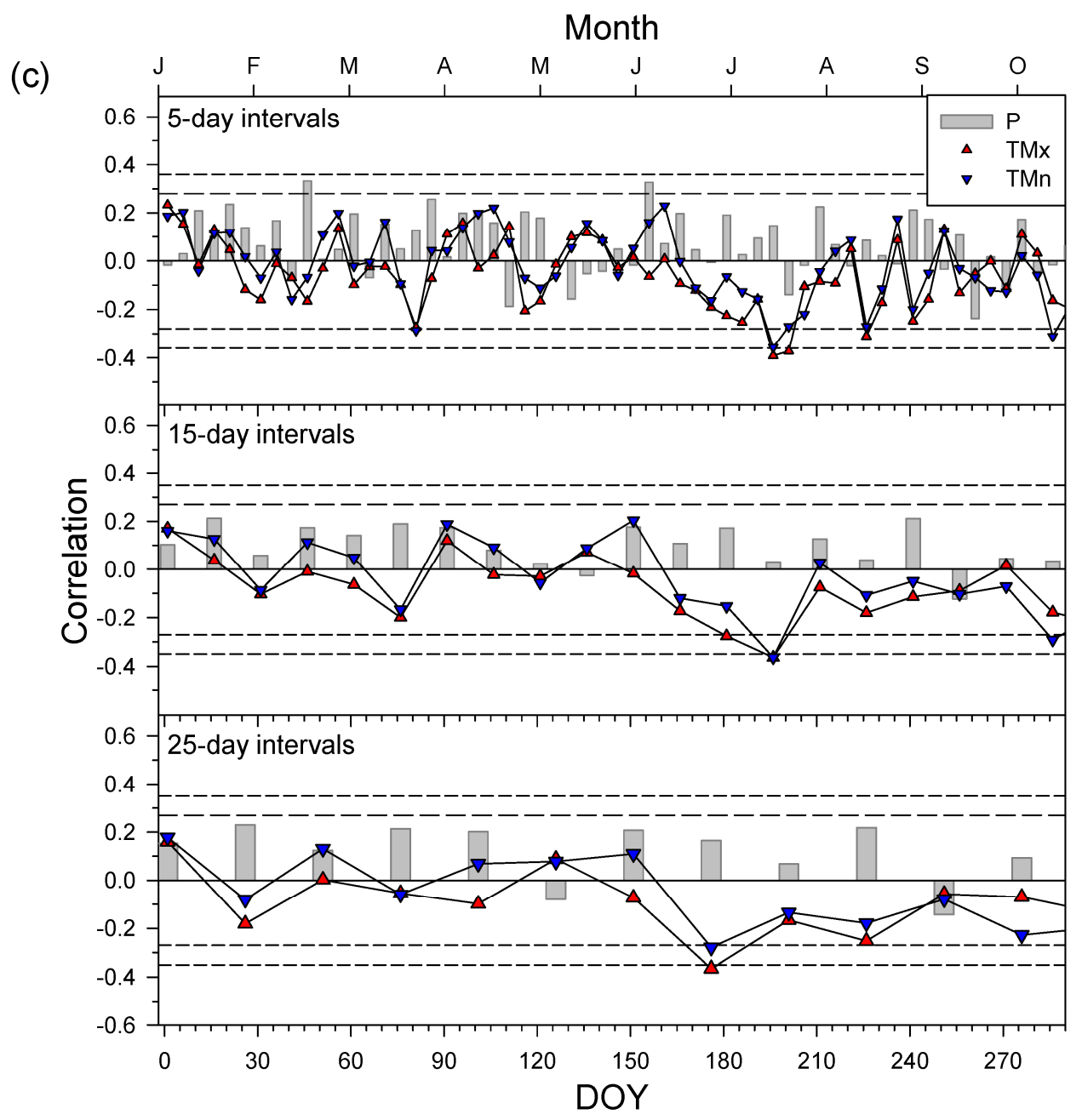

Figure 7. Responses of tree-ring width indices (period 1960-2014) to climate: monthly mean maximum (TMx) and minimum (TMn) temperatures and total precipitation (a), the SPEI drought index calculated for 1-16-month-long scales (b) and daily climate data averaged (temperatures) or summed (precipitation) for 5-, 15- and 25-day-long scales (c). All plots show Pearson correlations. In figures (a) and (c) the dashed and dotted lines indicate 0.05 and 0.01 significance levels, whereas in (b) the box indicates correlations with $p<0.05$. In (a) correlations were calculated from previous October to current September and the months previous to the year of tree-ring formation are abbreviated by lowercase letters. In (b) the months are indicated along the $y$-axis, whilst in (a) and (c), correlations are shown along the $y$-axis. DOY - day of the year.

Table 2. Dendrochronological data and statistics (AC1, first-order autocorrelation; MSx: Mean sensitivity; EPS: Expressed Population Signal) of the holm oak tree-ring width chronology.

\begin{tabular}{|c|c|c|c|c|c|c|c|}
\hline \multirow{2}{*}{\multicolumn{3}{|c|}{ Data }} & \multicolumn{5}{|c|}{ Statistics } \\
\hline & & & \multicolumn{2}{|c|}{ Raw Data } & \multicolumn{3}{|c|}{ Residual Chronology } \\
\hline $\begin{array}{c}\text { No. trees } \\
\text { (sites } 1,2,3)\end{array}$ & Mean interval & Age (years) & $\begin{array}{c}\text { Tree-ring } \\
\text { width }(\mathrm{mm})\end{array}$ & $\mathrm{AC} 1$ & MSx & Correlation between trees & EPS \\
\hline $18(8,3,7)$ & $1955-2014$ & $59 \pm 16$ & $0.79 \pm 0.46$ & 0.43 & 0.47 & 0.24 & 0.74 \\
\hline
\end{tabular}




\subsection{Holm Oak Defoliation at National Level}

The main associations found between holm oak mean defoliation across Spain and any of the assessed climatic variables were with April mean temperature $(r=0.67, p=0.0006)$ and the October SPEI calculated at one-month-long scale $(r=-0.47, p=0.03)$ (Figure 8). Defoliation also responded positively to April temperatures of the previous year $(r=0.44, p=0.049)$. This is due to the fact that defoliation, but not April temperature, showed a significant $(p<0.05)$ and positive partial autocorrelation coefficient at a lag of one year. Years characterized by severe drought across Spain showed high defoliation levels (e.g., 1995, 2005 and 2012).

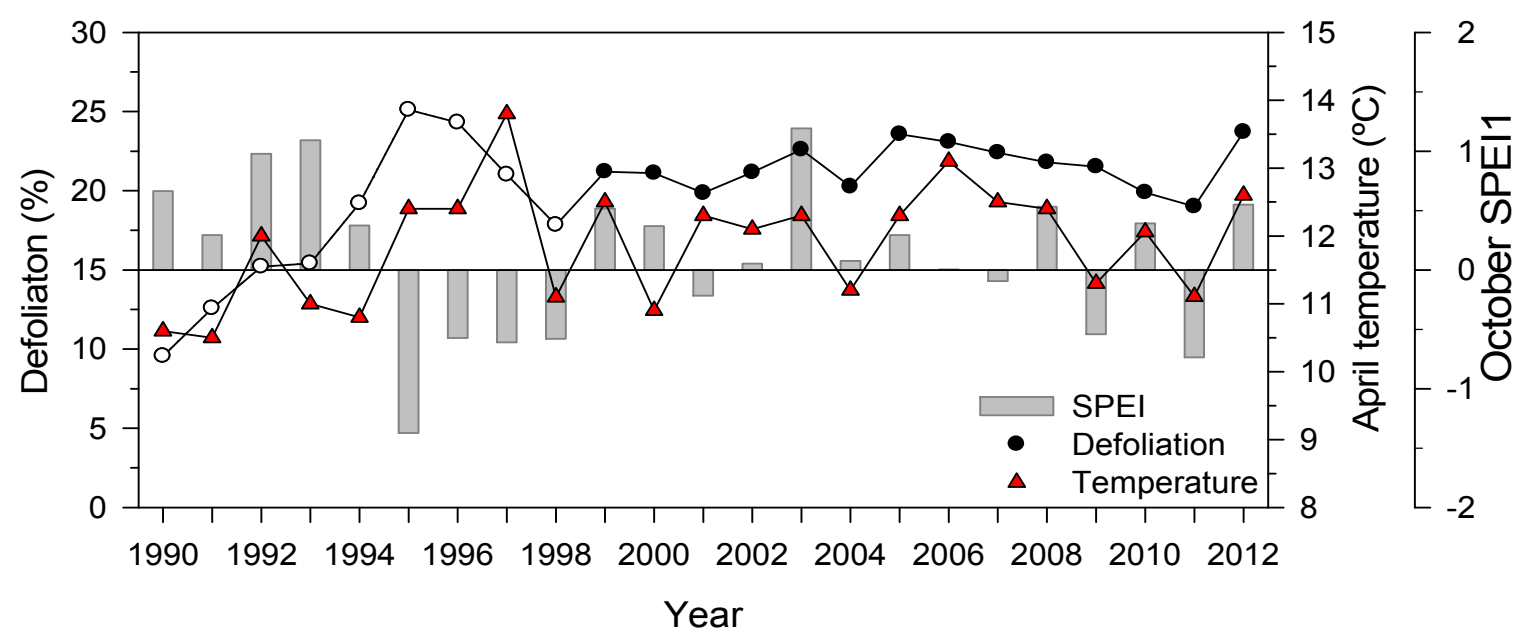

Figure 8. Defoliation levels (circles) of Spanish holm oak forests obtained for the period 1990-2012 as related to climatic variables (triangles, April temperatures; bars, October SPEI for one-month-long scales). The empty and filled circles of defoliation levels indicate two periods with different sample sizes: ca. 2400 (period 1990-1998) and ca. 3200 (period 1999-2012) trees, respectively.

\section{Discussion}

\subsection{How Drought Reduces Primary Growth and Generates Asynchrony Depends on its Timing}

Obviously, two drought years and three study stands are insufficient to draw robust conclusions about the relationships between drought characteristics and forest responses, but interesting differences in growth responses arise between the two compared events and those responses are supported by the presented eight-year-long continuous phenological monitoring based on 150 trees. The 2005 drought was characterized by very low precipitations during most of the growing season (April to September). This drought did not only cause growth reduction and a decline in forest productivity (NDVI), it also produced asynchrony among trees in their phenological patterns of primary growth (shoot production, foliar index). Holm oak is able to produce viable buds, which can be up to four years old [33]. Therefore, this species responds to very dry spring conditions with a reduced bud burst and leaf flush and by shedding old leaves, which diminish the transpiring leaf area and decrease additional water loss through the canopy [46]. This plastic behavior in primary growth is also illustrated by the abundant 
epicormic bud sprouting in response to drought [47] or by the uncommon bud bursting in response to autumn rains as observed in 2012. Nevertheless, such autumn bursting was not important at the stand scale since we detected a decline in NDVI in late summer 2012. The 2012 drought was characterized by very high temperatures before the start of the growing season (January, March) and at its end (August), probably leading to elevated evapotranspiration rates and vapor pressure deficit prior to bud burst and shoot elongation in spring and also during leaf maturation in late summer. Only in 2004 and 2012 we found a much lower shoot production in autumn than in spring. This indicates that the effects of the 2012 drought on primary growth intensified after the spring leaf flush through an enhanced shoot abscission and leaf loss. This is similar to what was observed in 2004 when most old leaves and shoots were shed after a masting event occurred in autumn 2003 [26]. In that aforementioned study and here, we did not observe that the 2003 masting event could lead to confounding effects on radial growth in 2005, since trees recovered quickly in 2004 by producing new leaves, but drought-masting interactions should also be considered in further studies. Therefore, both drought during the growing season and masting can lead to a loss in forest productivity by inducing a massive loss of old leaves (defoliation) and shoot abscission which can be regarded as self-pruning processes. In this way the tree returns to a more stable ratio between the stem conductive and canopy transpiring areas.

\subsection{Drought Diminishes Secondary Growth due to Water Shortage and Elevated Temperatures}

Drought severity during the growing season has been increasing in the study area since the 1950s. Such aridification process is negatively affecting radial growth and the forests ability to sequester carbon and retain it as long-term woody pools should also decrease. This is consistent with the strong response of wood formation to the water deficit from June to August, and particularly the negative effects of very warm conditions in July, particularly at 5-15-day-long scales, which has been observed in several holm oak forests across the Western Mediterranean Basin [43]. Note, however, that the relationships observed between short-term climatic conditions and growth should be confirmed with xylogenesis analyses describing the phenology of wood formation as summer drought proceeds. Such drought stress seems to be mainly driven by very warm conditions, which increase evapotranspiration rates and reduce the soil water available to grow. However, our observational approach does not allow excluding other factors such as heat stress indirectly enhancing respiration and reducing carbohydrates available to allow xylem cells dividing, expanding and lignifying.

\subsection{Primary and Secondary Decline in Response to Drought but Show Different Resiliencies}

Remote sensing and primary growth data were coupled through time, whereas secondary growth was uncoupled. Both the leaf production (foliar index) and forest productivity covaried and recovered one year after the 2005 drought, whereas radial growth was less resilient and showed legacy effects. This finding indicates that drought legacies should be better understood to properly quantify and model lagged forests responses to droughts in terms of wood formation and carbon uptake [21]. Radial growth took two years to recover values similar to those observed before the drought, which is not surprising since year-to-year persistence is a usual feature in ring-width series [38]. Those legacies can be caused by the adverse effects of drought stress through hydraulic deterioration leading to reduced growth rates one year after the drought even if climatic conditions are favorable to grow $[48,49]$. 


\subsection{Implications to Understand how Drought and Temperature Cause Defoliation}

Defoliation of holm oak across Spain increased as April conditions warmed as already found before [24] and, secondarily, as autumn conditions became drier [22]. Therefore, Spanish defoliation data seem to capture a mixed signal related both to heat-triggered or drought-induced massive leaf loss and probably reduced leaf flushing due to minimum budburst. Maxima defoliation values coincides with severe droughts but were also observed in wet but warm years (e.g., 2003). Consequently, the value of defoliation as a proxy of drought-related holm oak dieback should be critically examined given its high responsiveness to very warm conditions in spring. Defoliation can also be a very noisy variable reflecting drought and other stressors (insects, fungi) or corresponding to different processes (compare low leaf flushing vs. intense shedding of old leaves). Shoot production and NDVI were reliable proxies of the decline in productivity caused by drought, whereas radial growth captured the reduction of aboveground biomass. Thus, this research supports the use of additional proxies of tree vigor in studies of forest dieback related to either primary (shoot production, budburst) or secondary growth (tree-ring width).

Primary and secondary growth do interact in trees and may show trade-offs $[33,50]$. We argue that further effort should be made to disentangle how the phenology and amount of primary and secondary growth types interact in response to droughts of different timings and intensities [51-54]. Specifically, the response of budburst to spring droughts occurring before leaf flushing (e.g., 2005) merits further research. Severe water shortage precluded bud bursting and stopped shoot development making trees dependent on old leaves formed in previous years. Such drastic reduction aboveground biomass increase translated into a low amount of stem wood formation. More frequent droughts of this type will probably impair the ability to growth and uptake carbon of trees in Mediterranean areas. Post-drought recovery of many of these oak forests will depend on the tree species capacity to resprout [33].

\section{Conclusions}

We report diverse growth responses to two different droughts $(2005,2012)$ in three holm oak stands. Drought reduced shoot production, enhanced the shedding of old leaves, decreased forest productivity (NDVI) and stem wood formation and enhanced asynchrony in primary growth (budburst, shoot elongation). Defoliation and radial-growth decline were more pronounced in the 2012 than in the 2005 drought despite in 2005 spring primary growth was the lowest. The 2012 drought was characterized by a dry previous winter and very warm conditions from that season until summer, whereas in 2005 spring and early summer were dry and hot leading to phenological asynchrony due to a very low rate of budburst, i.e., most trees did not show spring leaf flush. Defoliation in autumn peaked in 2012 in response to dry conditions during the growing season and in the previous winter. However, the decline in forest productivity observed in spring-summer 2005 corresponded to a low shoot and leaf production. Droughts of different timings and intensities generated diverse responses in holm oak related to forest phenology (asynchrony, budburst, leaf flushing), productivity (shoot production, defoliation, NDVI), and biomass changes (shoot and leaf biomass, wood formation). We argue that a more comprehensive approach to predict and understand warming- and drought-induced 
forest dieback should deal with proxies or variables linking primary and secondary growth responses to droughts of different climatic characteristics (timing, duration, intensity, thermal conditions).

\section{Acknowledgments}

We thank Gabriel Montserrat-Martí for fruitful discussions during the numerous campaign samplings and for developing the phenological scales used in this study based on her meticulous processing of branches. We also thank all people who contributed to obtain the field data (J. Albuixech, M. Altarriba, A.Q. Alla, P. Sánchez). We thank the editor and the two reviewers for their helpful comments.

\section{Author Contributions}

J. Julio Camarero performed field sampling, data analyses and led the writing. Magí Franquesa carried out the analyses of remote-sensing data and mapped the trees. Gabriel Sangüesa-Barreda performed the dendrochronological analyses with contributions by J. Julio Camarero. All authors contributed to discussion and to the final writing of the manuscript.

\section{Conflicts of Interest}

The authors declare no conflict of interest.

\section{References}

1. Gutschick, V.P.; BassiriRad, H. Extreme events as shaping physiology, ecology, and evolution of plants: Toward a unified definition and evaluation of their consequences. New Phytol. 2003, 160, $21-42$.

2. Poulter, B.; Frank, D.; Ciais, P.; Myneni, R.B.; Andela, A.; Bi, J.; Broquet, G.; Canadell, J.G.; Chevallier, F.; Liu, Y.Y.; et al. Contribution of semi-arid ecosystems to interannual variability of the global carbon cycle. Nature 2014, 509, 600-603.

3. Bonan, G.B. Forests and climate change: Forcings, feedbacks, and the climate benefits of forests. Science 2008, 320, 1444-1449.

4. Chaves, M.M.; Oliveira, M.M. Mechanisms underlying plant resilience to water deficits: Prospects for water-saving agriculture. J. Exp. Bot. 2004, 55, 2365-2384.

5. Bréda, N.; Huc, R.; Granier, A.; Dreyer, E. Temperate forest trees and stands under severe drought: A review of ecophysiological responses, adaptation processes and long-term responses. Ann. For. Sci. 2006, 63, 625-644.

6. Allen, C.D.; Macalady, A.K.; Chenchouni, H.; Bachelet, D.; McDowell, N.; Vennetier, M.; Kitzberger, T.; Rigling, A.; Breshears, D.D.; Hogg, E.H.; et al. A global overview of drought and heat-induced tree mortality reveals emerging climate change risks for forests. For. Ecol. Manag. 2010, 259, 660-684.

7. McDowell, N.; Pockman, W.T.; Allen, C.D.; Breshears, D.D.; Cobb, N.; Kolb, T.; Plaut, J.; Sperry, J.; West, A.; Williams, D.G.; et al. Mechanisms of plant survival and mortality during drought: Why do some plants survive while others succumb to drought? New Phytol. 2008, 178, 719-739. 
8. Bigler, C.; Bräker, O.U.; Bugmann, H.; Dobbertin, M.; Rigling, A. Drought as an inciting mortality factor in Scots pine stands of the Valais, Switzerland. Ecosystems 2006, 9, 330-343.

9. De Boeck, H.J.; Dreesen, F.E.; Janssens, I.A.; Nijs, I. Climatic characteristics of heat waves and their simulation in plant experiments. Glob. Chang. Biol. 2010, 16, 1992-2000.

10. Larcher, W. Physiological Plant Ecology, 4th ed.; Springer-Verlag: Berlin, Germany, 2003.

11. McDowell, N.G.; Beerling, D.J.; Breshears, D.D.; Fisher, R.A.; Raffa, K.F.; Stitt, M. The interdependence of mechanisms underlying climate-driven vegetation mortality. Trends Ecol. Evol. 2011, 26, 523-532.

12. Williams, A.P.; Allen, C.D.; Macalady, A.K.; Griffin, D.; Woodhouse, C.A.; Meko, D.M.; Swetnam, T.W.; Rauscher, S.A.; Seager, R.; Grissino-Mayer, H.D.; et al. Temperature as a potent driver of regional forest drought stress and tree mortality. Nat. Clim. Chang. 2012, 3, 292-297.

13. Anderegg, W.R.L.; Kanem, J.M.K.; Anderegg, L.D. Consequences of widespread tree mortality triggered by drought and temperature stress. Nat. Clim. Chang. 2013, 3, 30-36.

14. Ruffault, J.; Martin-St Paul, N.K.; Rambal, S.; Mouillot, F. Differential regional responses in drought length; intensity and timing to recent climate changes in a Mediterranean forested ecosystem. Clim. Chang. 2013, 117, 103-117.

15. Mueller, B.; Seneviratne, S. Hot days induced by precipitation deficits at the global scale. Proc. Natl. Acad. Sci. USA 2012, 109, 12398-12403.

16. Montserrat-Martí, G.; Camarero, J.J.; Palacio, S.; Pérez-Rontomé, C.; Milla, R.; Albuixech, J.; Maestro, M. Summer-drought constrains the phenology and growth of two co-existing Mediterranean oaks with contrasting leaf habit: Implications for their persistence and reproduction. Trees: Struct. Funct. 2009, 23, 787-799.

17. Peñuelas, J.; Lloret, F.; Montoya, R. Severe drought effects on Mediterranean woody flora in Spain. For. Sci. 2001, 47, 214-218.

18. Lloret, F.; Siscart, D.; Dalmases, C. Canopy recovery after drought dieback in holm-oak Mediterranean forests of Catalonia (NE Spain). Glob. Chang. Biol. 2004, 10, 2092-2099.

19. Ogaya, R.; Peñuelas, J. Tree growth, mortality, and above-ground biomass accumulation in a holm oak forest under a five-year experimental field drought. Plant Ecol. 2007, 189, 291-299.

20. Camarero, J.J.; Gazol, A.; Sangüesa-Barreda, G.; Oliva, J.; Vicente-Serrano, S.M. To die or not to die: Early-warning signals of dieback in response to a severe drought. J. Ecol. 2005, 103, 44-57.

21. Anderegg, W.R.L.; Plavcová, L.; Anderegg, L.D.L.; Hacke, U.G.; Berry, J.A.; Field, C.B. Drought's legacy: Multiyear hydraulic deterioration underlies widespread aspen forest die-off and portends increased future risk. Glob. Chang. Biol. 2013, 19, 1188-1196.

22. Carnicer, J.; Coll, M.; Ninyerola, M.; Pons, X.; Sánchez, G.; Peñuelas, J. Widespread crown condition decline, food web disruption, and amplified tree mortality with increased climate change-type drought. Proc. Natl. Acad. Sci. USA 2011, 108, 1474-1478.

23. Manzano Serrano, M.J.; Sánchez Peña, G.; San Pedro Santiado, D.; Torres Martínez, B. Vitalidad de Quercus ilex durante los últimos 26 años. Dinámica e identificación de áreas críticas desde el punto de vista sanitario. In Montes, Servicios y Desarrollo Rural, $6^{\circ}$ Congreso Forestal Español; SECF: Vitoria, Spain, 2013; pp. 2-11. 
24. De la Cruz, A.C.; Gil, P.M.; Fernández-Cancio, A.; Minaya, M.; Navarro-Cerrillo, R.M.; Sánchez-Salguero, R.; Grau, J.M. Defoliation triggered by climate induced effects in Spanish ICP Forests monitoring plots. For. Ecol. Manag. 2014, 331, 245-255.

25. Peguero-Pina, J.J.; Sancho-Knapik, D.; Barrón, E.; Camarero, J.J.; Vilagrosa, A.; Gil-Pelegrín, E. Morphological and physiological divergences within Quercus ilex support the existence of different ecotypes depending on climatic dryness. Ann. Bot. 2014, 114, 301-313.

26. Camarero, J.J.; Albuixech, J.; López-Lozano, R.; Casterad, M.A.; Montserrat-Martí, G. An increase in canopy cover leads to masting in Quercus ilex. Trees: Struct. Funct. 2010, 24, 909-918.

27. Dobbertin, M. Tree growth as indicator of tree vitality and of tree reaction to environmental stress: A review. Eur. J. For. Res. 2005, 124, 319-333.

28. Schomaker, M.E.; Zarnoch, S.J.; Bechtold, W.A.; Latelle, D.J.; Burkman, W.G.; Cox, S.M. Crown-Condition Classification: A Guide to Data Collection and Analysis; General Technical Report; SRS-102; USDA, Forest Service, Southern Research Station: Asheville, NC, USA, 2007.

29. Hargreaves, G.H.; Samani, Z.A. Estimating potential evapotranspiration. J. Irrig. Drain. Eng. 1982, 108, 225-230.

30. Vicente-Serrano, S.M.; Beguería, S.; López-Moreno, J.I. A multiscalar drought index sensitive to global warming: The standardized precipitation evapotranspiration index. J. Clim. 2010, 23, 1696-1718.

31. Vicente-Serrano, S.M.; Camarero, J.J.; Azorín-Molina, C. Diverse responses of forest growth to drought time-scales in the Northern Hemisphere. Glob. Ecol. Biogeogr. 2014, 23, 1019-1030.

32. Harris, I.; Jones, P.D.; Osborn, T.J.; Lister, D.H. Updated high-resolution grids of monthly climatic observations-The CRU TS3.10 dataset. Int. J. Climatol. 2014, 34, 623-642.

33. Alla, A.Q.; Camarero, J.J.; Palacio, S.; Montserrat-Martí, G. Revisiting the fate of buds: Size and position drive bud mortality and bursting in two coexisting Mediterranean Quercus species with contrasting leaf habit. Trees: Struct. Funct. 2013, 27, 1375-1386.

34. Masek, J.G.; Vermote, E.F.; Saleous, N.; Wolfe, R.; Hall, F.G.; Huemmrich, F.; Gao, F.; Kutler, J.; Lim, T.K. LEDAPS Landsat Calibration, Reflectance, Atmospheric Correction Preprocessing Code; Oak Ridge National Laboratory Distributed Active Archive Center: Oak Ridge, TN, USA, 2012.

35. Bannari, A.; Morin, D.; Bonn, F.; Huete, A.R. A review of vegetation indices. Remote Sens. Rev. 1995, 13, 95-120.

36. Tucker, C.J.; Vanpraet, C.L.; Sharman, M.J.; Vanittersum, G. Satellite remote-sensing of total herbaceous biomass production in the Senegalese Sahel-1980-1984. Remote Sens. Environ. 1985, 17, 233-249.

37. Hardisky, M.A.; Klemas, V.; Smart, R.M. The influences of soil salinity, growth form, and leaf moisture on the spectral reflectance of Spartina alterniflora canopies. Photogramm. Eng. Remote Sens. 1983, 49, 77-83.

38. Fritts, H.C. Tree Rings and Climate, 2nd ed.; Blackburn Press: Caldwell, NJ, USA, 2001.

39. Holmes, R.L. Computer-assisted quality control in tree-ring dating and measurement. Tree-Ring Bull. 1983, 43, 69-78. 
40. Cook, E.R. A Time Series Analysis Approach to Tree-Ring Standardization. Ph.D. Thesis, University of Arizona, Tucson, AZ, USA, 5 August 1985.

41. Wigley, T.M.L.; Briffa, K.R.; Jones, P.D. On the average value of correlated time series, with applications in dendroclimatology and hydrometeorology. J. Appl. Meteorol. Climatol. 1984, 23, 201-213.

42. Cook, E.; Kairiukstis, L. Methods of Dendrochronology: Applications in the Environmental Sciences, 1st ed.; Kluwer: Dordrecht, The Netherlands, 1990.

43. Gutiérrez, E.; Campelo, F.; Camarero, J.J.; Ribas, M.; Muntán, E.; Nabais, C.; Freitas, H. Climate controls act at different scales on the seasonal pattern of Quercus ilex L. stem radial increments in NE Spain. Trees: Struct. Funct. 2011, 25, 637-646.

44. International Cooperative Programme on Assessment and Monitoring of Air Pollution Effects on Forests (ICP). Manual on Methods and Criteria for Harmonized Sampling, Assessment, Monitoring and Analysis of the Effects of Air Pollution on Forests Part IV: Visual Assessment of Crown Condition and Damaging Agents; UNECE, ICP Forests: Hamburg, Germany, 2010.

45. R Development Core Team. R: A Language and Environment for Statistical Computing; $\mathrm{R}$ Foundation for Statistical Computing: Vienna, Austria, 2014.

46. Misson, L.; Degueldre, D.; Collin, C.; Rodriguez, R.; Rocheteau, A.; Ourcival, J.M.; Rambal, S. Phenological responses to extreme droughts in a Mediterranean forest. Glob. Chang. Biol. 2011, 17, 1036-1048.

47. Meier, A.R.; Saunders, M.R.; Michler, C.H. Epicormic buds in trees: A review of bud establishment, development and dormancy release. Tree Physiol. 2012, 32, 565-584.

48. McDowell, N. Mechanisms linking drought, hydraulics, carbon metabolism, and vegetation mortality. Plant Physiol. 2011, 155, 1051-1059.

49. Corcuera, L.; Camarero, J.J.; Gil-Pelegrín, E. Effects of a severe drought on Quercus ilex radial growth and xylem anatomy. Trees: Struct. Funct. 2004, 18, 83-92.

50. Colin, F.; Sanjines, A.; Fortin, M.; Bontemps, J.-D.; Nicolini, E. Fagus sylvatica trunk epicormics in relation to primary and secondary growth. Ann. Bot. 2012, 110, 995-1005.

51. Ogaya, R.; Barbeta, A.; Başnou, C.; Peñuelas, J. Satellite data as indicators of tree biomass growth and forest dieback in a Mediterranean holm oak forest. Ann. For. Sci. 2015, 72, 135-144.

52. Gratani, L.; Bombelli, A. Correlation between leaf age and other leaf traits in three Mediterranean maquis shrub species: Quercus ilex, Phillyrea latifolia and Cistus incanus. Environ. Exp. Bot. 2000, 43, 141-153.

53. Bussotti, F.; Bettini, D.; Grossoni, P.; Mansuino, S.; Nibbi, R.; Soda, C.; Tani, C. Structural and functional traits of Quercus ilex in response to water availability. Environ. Exp. Bot. 2002, 47, 11-23.

54. Ogaya, R.; Peñuelas, J. Phenological patterns of Quercus ilex, Phyllirea latifolia, and Arbutus unedo growing under a field experimental drought. Écoscience 2004, 11, 263-270.

(C) 2015 by the authors; licensee MDPI, Basel, Switzerland. This article is an open access article distributed under the terms and conditions of the Creative Commons Attribution license (http://creativecommons.org/licenses/by/4.0/). 